Review

\title{
Human Trabecular Meshwork Progenitors
}

\author{
Qin Zhu ${ }^{1}$, Yuan Zhang ${ }^{2}$, Sean Tighe ${ }^{2}$, Yongsong Liu ${ }^{3}$, Yingting Zhu ${ }^{2}$ and Min $\mathrm{Hu}^{1}{ }^{\bowtie}$ \\ 1. Department of Ophthalmology, Fourth Affiliated Hospital of Kunming Medical University (the Second People's Hospital of Yunnan Province); Yunnan Eye \\ Institute; Key Laboratory of Yunnan Province for the Prevention and Treatment of ophthalmology (2017DG008); Provincial Innovation Team for Cataract \\ and Ocular Fundus Disease, The Second People's Hospital of Yunnan Province (2017HC010); Expert Workstation of Yao Ke (2017IC064), Kunming 650021, \\ China \\ 2. Tissue Tech, Inc., Ocular Surface Center, and Ocular Surface Research \& Education Foundation, Miami, FL, 33173 USA \\ 3. Department of Ophthalmology, Yan' An Hospital of Kunming City, Kunming, 650051, China
}

$\square$ Corresponding authors: Min Hu, M.D., Ph.D. Department of Ophthalmology, Fourth Affiliated Hospital of Kunming Medical University, Second People's Hospital of Yunnan Province, Kunming 650021, China; Telephone: 0118615087162600; Fax: 011860871-65156650; E-mail: fudanhumin@sina.com or Yingting Zhu, Ph.D. TissueTech, Inc., 7000 SW 97th Avenue, Suite 212, Miami, FL 33173. Telephone: (786) 456-7632; Fax: (305) 274-1297; E-mail: yzhu@tissuetechinc.com

(c) Ivyspring International Publisher. This is an open access article distributed under the terms of the Creative Commons Attribution (CC BY-NC) license (https://creativecommons.org/licenses/by-nc/4.0/). See http://ivyspring.com/terms for full terms and conditions.

Received: 2018.12.07; Accepted: 2019.03.04; Published: 2019.05.10

\begin{abstract}
Trabecular meshwork (TM) cells are a group of progenitors that have the ability to become adipocytes, chondrocytes and endothelial cells. Therefore, those adult corneal progenitors may be used as an effective therapy for trabecular meshwork diseases such as glaucoma, corneal endothelial dysfunctions such as blindness due to corneal endothelial dysfunction, and similar diseases. In order to promote the understanding of human trabecular meshwork progenitors, this article reviews human trabecular meshwork progenitor therapy and discusses its potential applications for curing human eye blindness.
\end{abstract}

Key words: trabecular meshwork, progenitor, cell-based therapy, glaucoma

\section{Trabecular Meshwork Cells}

The TM cells are a group of cells at the base of the cornea next to the ciliary body. We have used collagenase digestion for isolation of the TM cells since it does not disrupt cell-cell junctions and thus retains the cell phenotype [1]. Because to retain the progenitor status and phenotype is important for the expansion and subsequent clinical applications, we have used the stem cell culture medium MESCM and $5 \%$ FBS for their expansion [1].

\section{Phenotype of TM Progenitors}

Previously, AQP1, MGP, CHI3L1, TIMP3 were used as TM markers [2]:

- The water channel aquaporin 1 (AQP1) has been detected in the TM in vivo [3] as well as in cultured human TM cells and plays an important role in modulation of aqueous outflow [4]

- Matrix Gla protein (MGP) has the ability to function in the TM as a calcification inhibitor [5] and may be a key contributor to IOP homeostasis by regulating calcification and hardening of the TM [3]

- Aqueous humor contains chitinase 3-like 1 (CHI3L1) has a protective role against inflammation, ECM remodeling, and cell death in the outflow pathway

- TIMP3 (Metalloproteinase inhibitor 3) is an inhibitor of the matrix metalloproteinases, a group of peptidases involved in degradation of the extracellular matrix (ECM) (Forsius, 1982)

Recently, AnkG and MUC1 have been identified as TM markers. AnkG was described as essential for production of new neurons in the brain [6], which is responsible for cell regeneration in the TM. MUC1 is a cell surface mucin identified to be abundantly expressed in TM cells [2]. Based on the above, normal TM markers should include AQP1, MGP, CHI3L1, TIMP3, AnkG, MUC1.

\section{Substrate and Culture Media for TM Progenitor Cells}

The capacity of differentiated cells to re-acquire a 
totipotent state was first revealed when the nuclei of differentiated cells were reprogrammed in enucleated oocytes to generate frogs [7]. In addition, ectopic expression of just four transcription factors, Oct4, Klf4, c-Myc, and Sox2 (OKMS), is sufficient to reprogram somatic cells to induced pluripotent stem cells (iPSC) [8]. Fully reprogrammed iPSCs have a similar developmental potential as ESC [9]. At the molecular level, reprogramming results in large changes in gene expression that remodel the somatic cell properties to a state similar to embryonic stem cells [10] that include early activation of the pluripotency markers alkaline phosphatase (AP) and SSEA1 [11] followed by embryonic stem cell factors such as Oct4, Sox2, and Klf4 themselves, as well as Nanog and Sall4 [12-14]. These markers have been shown to be upregulated by culturing limbal niche cells on 3D Matrigel [15-21]. Although 3D Matrigel is known to upregulate embryonic stem cell markers in other cell types, it remains unclear whether TM cells could be reprogrammed on 3D Matrigel.

Because the culture media in all the published articles contained FBS, ranging from $5 \%$ to $20 \%$, fetal bovine serum (FBS) should be important in culturing TM cells. Repeated experiment shows that TM cells do not grow well in MESCM without FBS at P1 and stop growing at P3 with enlarged shape and cell debris (dead cells). The total number of doubling is 7 . In contrast, TM cells cultured in MESCM+5\% FBS could be expanded to P8 with a total cell doubling of 16 . Based on our experiment results, culture of TM cells in MESCM+5\% FBS, not MESCM alone on 2D Matrigel is the best condition for their expansion TM cells can be isolated by collagenase and expanded on coated Matrigel in MESCM+5\%FBS up to 7 passages with 16 cell doublings [1]. Immunostaining showed that these cells at the time of isolation (D0) expressed TM markers such as AQP1, CHI3L1, MGP and AnkGs [1], similar to what have been previously reported [22, 23]. Compared with that of the D0 cluster immediately isolated by collagenase, qRT-PCR revealed a significant decline in expression of these markers as well as ESC and NC markers by P2 cells [1], suggesting that $2 \mathrm{D}$ matrigel cannot retain their progenitor status. This conclusion was confirmed by qTR-PCR of TM cell markers, ESC and NC markers. Although P0 TM cells cultured in MESCM express more TM cell markers such as CHI3L1, MGP and AnkG, TM cells cultured in MESCM $+5 \%$ FBS expressed more ESC and NC markers except similar expression of PDGFR $\beta$, suggesting that MESCM $+5 \%$ FBS is a better culture medium for TM cells. Interestingly, the expression of ESC and NC markers reduced significantly after passages.

When reseeded on 3D Matrigel at P3 for 2 days following the method from $\mathrm{Li}[24,25]$, these cells formed spheres, but not from P2 cells on coated Matrigel. Addition of Noggin abolished nuclear translocation of Nanog in cells seeded on 3D Matrigel [1]. In addition, the transcript level of TM cell markers CHI3L1, MGP, AnkG, ESC and NC markers Klf4, Nanog, Oct4, Sox2, SSEA4, Foxd3, Msx10, Sox9, Sox10 and PDGFR $\beta$ was significantly increased compared that from P2 cells. Such upregulation of TM, ESC and NC markers except TM marker CHI3L1, ABCG2, Myc, Nestin, p75NTR and N-cadherin was attenuated by addition of Noggin [1]. Those results suggest that TM cells can be reprogrammed into younger progenitors.

Expression of BMP2, 4 and 6 in TM cells was upregulated by 3D Matrigel using coated Matrigel as the control [1]. In addition, BMP receptor 2 (BMPR2) was upregulated in TM cells in 3D Matrigel, while BMPR1B downregulated [1]. Immunostaining showed that pSmad1/5/8 was located in nucleus in TM cells on 3D Matrigel but not those on coated Matrigel [1]. Those results suggest that canonical BMP signaling is activated in TM cells on 3D Matrigel. The activation of canonical BMP signaling was coupled with higher transcript expression of embryonic stem cell (ESC) markers, such as Oct4, Sox2, Nanog, Klf4 and SSEA4 and that of neural crest markers, such as FoxD3, MSX1, Sox9, Sox10 and PDGFR $\beta$ [1]. Correspondingly, positive nuclear immunostaining of Oct4, Sox2 and Nanog was also observed in 3D cells [1], suggesting that TM cells can be reprogrammed into their progenitor status on 3D Matrigel, similar to reprogramming of induced pluripotent stem cells (iPSCs) [19-21]. Such a conclusion is supported by that fact that BMP inhibitor, Noggin, could abolished up-regulation of BMP1, BMP2, BMP4, BMP6 and BMPR2 [1] and attenuated higher transcript expression of embryonic stem cell (ESC) markers Oct4, Sox2, Nanog, Klf4 and SSEA4 and neural crest markers FoxD3, MSX1, Sox9, Sox10 and PDGFR $\beta$ [1] and blocked nuclear translocation of Oct4, Sox2, Nanog and pSmad1/5/8 [1]. These data collectively suggest that canonical BMP signaling is activated in TM cells on 3D Matrigel to reprogram TM cells into their progenitor status.

We then examined if these progenitor cells could be differentiated into other cells types by culturing them in the medium designated for induction of adipose cells, osteocytes, chondrocytes, keratocyte and human corneal endothelial cells. Our results showed that the cells expanded both on coated Matrigel and 3D Matrigel could differentiate into adipocytes and human corneal endothelial-like cells [1]. For induction of corneal endothelium, the induced HCEC expressed cytoplasmic $\gamma$-tubulin and 
junctional p120, $\mathrm{N}$-cadherin, $\mathrm{a}$-catenin, $\beta$-catenin, Zona occludens protein 1 (ZO-1) and Na-K-ATPase, all of which are markers of HCEC $[1,26]$, suggesting TM cells could be induced to HCEC-like cells. Such expression of HCEC markers was consistent with the in vivo expression pattern previously reported by us [26-34]. The reprogrammed cells on 3D Matrigel had a significantly higher frequency of adipocytes stained by Oil Red $\mathrm{O}$ than cells cultured on coated Matrigel, suggesting the cells on 3D Matrigel were more potent than the cells on Matrigel coated-plastics for induction of adipocytes [1]. In addition, only the cells on 3D Matrigel could be stained by Alcian Blue [1], suggesting that the cells on 3D Matrigel have the potential for chondrogenesis. The induction of osteocytes and keratocytes was not successful evidently by no staining of matrix mineralization by Alizarin Red, and no staining of corneal stromal specific extracellular matrix by keratocan [2]. Therefore, we predict that trabecular meshwork progenitors are valuable resources for stem cell therapy for glaucoma and other diseases.

\section{Glaucoma}

Glaucoma causes irreversible blindness worldwide, linked to pathogenesis in TM cells [35]. It is estimated that by 2020, 80 million patients will suffer from glaucoma and 11.2 million of those people will develop bilateral blindness [36-38]. Glaucoma is classified into 2 categories: open-angle and angleclosure glaucoma. In USA, about $80 \%$ cases are open-angle glaucoma. Nevertheless, angle-closure glaucoma is severe with vision loss [39]. In its etiology process, elevated intraocular pressure (IOP) [40] cause optic nerve damage and lead to progressive visual loss [41]. Recent treatments for elevated IOP include reduction of aqueous humor by drugs and surgical improvement of outflow. The therapies are effective, however they have their limitations, for example, toxicity and complications. Despite enormous effort by scientists in this world, an effective treatment has not been established due to lack of understanding of glaucoma.

\section{Glaucoma Promoted by Collagen IV/Fibronectin in the Presence of TGF $\beta 1$ Through Canonical TGF $\beta$ Signaling}

Overexpression of collagen is linked to etiology of glaucoma. Synthesis of collagen increases the extracellular matrix (ECM) and may lead to TM obstruction and decreased outflow facility. Collagen synthesis can be upregulated by TGF- $\beta 2(\mathrm{Da}, 2004)$ and TM cells seeded on collagen with TGF- $\beta 1$ induces a myofibroblast-like phenotype, as reflected by a dose-dependent increase in the expression and production of a-smooth muscle actin (aSMA) in vitro [42]. Based on the above, it is likely that collagen participates in the development of glaucoma. In addition, fibronectin is also elevated in glaucoma TM tissues and AH [43-45]. Treatment of TM cells with TGF- $\beta 2$ upregulates expression of PAI1 and secretion of fibronectin [46]. Therefore, it is likely that fibronectin may be also involved in the development of glaucoma.

\section{The Components of Matrix Controlling TGF- $\beta$ Paradox in Human Eyes}

TGF- $\beta$ family includes TGF- $\beta 1$, TGF- $\beta 2$ and TGF- $\beta 3$. TGF- $\beta 2$ is the predominant TGF- $\beta$ isoform in the eye and is found in large amounts in the aqueous humor of the anterior eye [47-49], in the vitreous, neural retina and retinal pigmented epithelium in the posterior eye [50], in optic nerve [51] and in the normal trabecular meshwork [52]. In the aqueous humor of patients with primary open angle glaucoma (POAG), the amounts of TGF- $\beta 2$ are significantly increased [53, 54]. In addition, the amounts of TGF- $\beta 1$ in the aqueous humor have been reported to be higher than normal in eyes with pseudoexfoliation syndrome and pseudoexfoliation glaucoma [55]. More recently, an increase in the amounts of TGF- $\beta 3$ in the aqueous humor of eyes with pseudoexfoliation syndrome has also been reported [56]. In contrast, trabecular meshwork cells secrete TGF- $\beta 1$ and $-\beta 2$ when cultured [53].

TGF- $\beta$ has numerous effects in physiology and pathology. TGF- $\beta$ is synthesized and secreted as a tripartite complex, binding to its receptor for its actions. Sequestration of latent TGF- $\beta$ in ECM is crucial for proper mobilization of the latent cytokine and its activation. However, loss-of-function study suggest that mutations in genes of some matrix proteins that may bind TGF- $\beta$ cause increased, not decreased TGF- $\beta$ concentrations, being so called 'TGF- $\beta$ paradox' [57]. Latent TGF $\beta$ binding proteins (LTBP) latency associated peptide (LAP) and matrix metalloproteases (MMP), have the potential to modulate its signaling. Therefore, the ECM is not simply a storage depot for TGF- $\beta$, but a site at which cytokine availability is modulated to ensure proper crosstalk between TGF- $\beta$-responsive cells and the products of TGF- $\beta$-responsive genes.

In the interacting model, when ECM integrity is lost by aging, degeneration, inflammation or mutation and glaucoma, mesenchymal cells, such as fibroblasts or smooth muscle cells, detect the defective matrix. The response of the mesenchymal cell is to repair the failed matrix by generating active TGF- $\beta$ and to produce the required activators of latent TGF- $\beta$ as 
part of the repair process.

The production of TGF- $\beta 2$ in the eye is constitutive and considered to be from the iris and ciliary body cells [47, 49], however, TGF- $\beta 2$ is not released by cells in an active form [58]. The process of producing and secreting TGF- $\beta$ results in the release of latent TGF- $\beta$, consisting of mature TGF- $\beta$ bound to LAP. This small latent TGF- $\beta$ complex is bound to LTBP. TGF- $\beta$ activity is blocked when it is bound to LAP, with or without the latent TGF- $\beta$-binding protein. It is this large TGF- $\beta$ complex that is held in the extracellular matrix that sequesters TGF- $\beta$ until released by proteases that cleave the latent TGF- $\beta$-binding protein. When released, it is still in an inactive form of TGF- $\beta$ bound to LAP in the small latent TGF- $\beta$ complex. Therefore, an additional activation step is needed to free the active form of TGF- $\beta$ to bind its receptors.

TGF- $\beta$ activation can be achieved through MMP or tissue plasmin that cleaves the LAP to release TGF- $\beta$. However, integrin-induced activation of TGF- $\beta 2$ is not possible because the TGF- $\beta 2$ LAP lacks the necessary Arg-Gly-Asp motif to bind. Therefore, the finding of active TGF- $\beta 2$ in the aqueous humor means that it must result from increased levels of proteases within the anterior chamber, probably MMP. That is, MMP in TM matrix may control TGF $\beta$ paradox. In fact, IOP is kept under control by an MMP-based feedback mechanism, regulating outflow resistance of the trabecular meshwork, homeostatic ECM turnover in the trabecular meshwork is actualized by expression of MMP-1, -2, -3, -9, -12, and -14, as well as TIMP-2 [59]. Of all MMP family members, MMP-2 and its endogenous inhibitor TIMP-2 have received the most attention for glaucoma research [59]; however, also low amounts of MMP-3, $-7,-9$, and -12 and TIMP-1 were detected in aqueous humor. In addition, we should not ignore the importance of LTBP-2 because because LTBP-2 is essential for the development of ciliary zonule microfibrils [60] and a mutation in LTBP-2 cause congenital glaucoma in a cat modle [61]. In summary, we should focus on studies on MMP and LTBP, especially MMP-2 and LTBP-2 in the study of how Matrix control of TGF- $\beta$ paradox, transcriptionally, translationally and cyto-locationally at the beginning.

In POAG, increased level of TGF- $\beta 2$ are likely to induce trabecular meshwork ECM deposition [62]. Versican, a large extracellular matrix proteoglycan, can be upregulated by more than 4-fold in human TM cells with treatment of TGF- $\beta$, the increase of which is observed in ECM of glaucoma [63]. In addition, angiopoietin-like factor or cornea-derived transcript 6 (CDT6) can be profoundly upregulated by TGF $\beta$, which is in the same locus as GLC3B (glaucoma 3, a primary congenital glaucoma-associated gene) [63]. TGF- $\beta 1$ and $-\beta 2$ also increase the expression and the activity of the enzyme tissue transglutaminase [64, 65], which induces irreversible cross-linking of trabecular meshwork fibronectin, found in higher amounts and activity in that of patients with POAG $[65,66]$, increasing trabecular meshwork stiffness that has been observed in POAG [67]. TGF- $\beta 2$ signaling also influences the extracellular proteolytic system of the trabecular meshwork, as it induces the expression and activity of plasminogen activator inhibitor (PAI-1), which is a potent inhibitor of the activation of matrix metalloproteinases (MMP) [62]). Treatment of TM cells with TGF- $\beta 2$ upregulates expression of PAI1 and secretion of fibronectin, which is blocked by inhibitors of TGF $\beta R I$ [46], suggesting that this event is probably mediated through non-canonical TGF- $\beta$ signaling. Interestingly, higher than normal concentrations of PAI-1 have been observed in the aqueous humors of patients with POAG [68]. In addition, trabecular meshwork cells of POAG eyes demonstrate structures with features of actin geodesic domes called cross-linked actin networks (CLAN) and, more frequently, punctuate actin concentrations. Increased expression of CLAN has been demonstrated in glucocorticoid-treated and glaucomatous cultured trabecular meshwork cells and outflow pathway tissues [69]. Recent data indicate that CLANs can also be induced in trabecular meshwork cells upon treatment with TGF- $\beta 2$ [70], which can be used as a glaucoma marker in vitro [71]. The formation of CLAN in trabecular meshwork cells involves both the increased expression and the activation of $\operatorname{av} \beta 3$ integrins [72].

Two important in vitro models of induction of TM cells into glaucoma-like cells have been reported. Zhao et al. (2004) reported that primary human TM cells can be induced to glaucoma-like cells by culturing the cells on laminin coated silicone sheet in serum-free DMEM, treated with TGF- $\beta 1$ or TGF- $\beta 2$ (1 $\mathrm{ng} / \mathrm{ml}$ ) for $72 \mathrm{~h}$ before sample collection [63]. The results show that TGF- $\beta 1 / 2$ profoundly upregulates glaucoma markers such as versican and CDT6 [63]. Bouchemi et al. (2017) proposed P5 human TM cells are cultured in 3D Matrigel-embedded condition for 15 days, treated with TGF- $\beta 2$ (5 ng/ml) for $48 \mathrm{~h}$ [71]. Their results suggest that such a treatment promotes CLAN formation and intercellular space contraction [71], suggestive of successful induction of glaucoma like cells from TM cells [71]. Therefore, we suggest that we can establish an in vitro glaucoma model following these two key papers, in addition to other papers mentioned above, using versican, CDT6, transglutaminase, PAI1 and CLAN as the readout for the establishment of an in vitro glaucoma model. It is 
unclear whether the expression of glaucoma markers is increased after a series of passages. It is also unclear whether we can induce TM cells into glaucoma TM cells by addition of TGF $\beta 2$ on the 2D Matrigel. If so, whether such glaucoma TM cells can be reversed to normal TM cells when cultured on 3D Matrigel.

One interesting report [2] showed that passage 3 $\mathrm{TM}$ cells that were isolated by collagenase digestion on a non-adhesive substrate in SCGM exhibited clonal growth and were multipotent including being able to be differentiated into adipose-like cells. However, the authors cannot induce passage $3 \mathrm{TM}$ cells into keratocyte-like cells if cultured and expanded in SCGM. The authors claimed that if the cell aggregates isolated by collagenase digestion and cultured directly in keratocyte differentiation medium (advanced MEM, $10 \mathrm{ng} / \mathrm{ml} \mathrm{bFGF}, 0.1 \mathrm{mM}$ ascorbic acid), the cells have detectable karatocan by RT-PCR and immunostaining. Such a claim is questionable because the authors claimed that if the cell aggregates isolated by collagenase digestion and cultured directly in keratocyte differentiation medium, the cells have detectable karatocan by RT-PCR and immunostaining, but not the cells after passage. This raised the question that such induced "keratocytes" might actually from contamination of keratocytes during isolation because contaminated keratocytes may be eliminated after a series passages (for example, the results from $\mathrm{P} 3$ passage TM cells in Du's case and in our results from P3 TM cells does not support such a claim). All Du's findings were that TM cells could be induced into adipose like cells [2]. Therefore, it is important to thoroughly characterize TM progenitors using TM cell markers, embryo stem cell markers and neural crest progenitor markers.

\section{Conclusion}

Trabecular meshwork (TM) progenitors have stem cell characteristics and strong potential to differentiate into various types of cells such as corneal endothelial cells, chondrocytes and adipocytes. Those adult stem cells can be adopted as an effective therapy for glaucoma, blindness due to corneal endothelial dysfunction and other diseases as well. Therefore, the discoveries of human trabecular meshwork progenitor therapy may not only generate new applications for curing human eye blindness, but also provide the platform technology to the entire human medicine.

\section{Abbreviations}

$\mathrm{AP}$, alkaline phosphatase; AQP1, aquaporin 1; aSMA, alpha smooth muscle actin, bFGF, basic fibroblast growth factor; $\mathrm{BMP}$, bone morphological protein; BrdU, bromodeoxyuridine; CEC, corneal endothelial cell; CHI3L1, chitinase 3-like 1; CKI, cyclin-dependent kinase inhibitor; CLAN, crosslinked actin networks; CDT6, cornea-derived transcript 6; ECM, extracellular matrix; EGF, epithelial grow factor; EMT, endothelial-mesenchymal transition; ESC, embryonic stem cells; FBS, fetal bovine sewrum; FBN, fibrillins; GAP, GTPase-activating protein; GEF, guanine nucleotide exchange factor; GLC3B, glaucoma 3; HCEC, human corneal endothelial cells; IOP, intraocular pressure; iPSC, induced pluripotent stem cells; JNK, Jun N-terminal kinase; LIF, leukemia Inhibitory Factor; LNC, limbal niche cells; MAPK, mitogen-activated protein kinase; MGP, Matrix Gla protein; N-cadherin, neural cadherin; NC, neural crest; NFkB, nuclear factor $\kappa B$; PAI-1, plasminogen activator inhibitor; $\mathrm{P}$, passage; POAG, primary open angle glaucoma; SLC, small lantent complex; TIMP3, Metalloproteinase inhibitor 3; TM, trabecular meshwork; ZO-1, tight junction protein 1.

\section{Acknowledgements}

This review has been supported by the National Natural Science Foundation, China (Grant Number 81560168 , to Min $\mathrm{Hu}$ ) and by the National Eye Institute, National Institutes of Health (Grant Numbers R43 EY 02250201 and R44 EY 022502-02, to Yingting $\mathrm{Zhu})$.

\section{Authors' Contributions}

Qin Zhu drafted the manuscript. Sean Tighe and Yongsong Liu participated in collecting information and professional English editing. Yingting Zhu and $\mathrm{Min} \mathrm{Hu}$ directed the work and finalized the manuscript.

\section{Competing Interests}

The authors have declared that no competing interest exists.

\section{References}

1. Zhang Y, Cai S, Tseng SCG, Zhu YT. Isolation and Expansion of Multipotent Progenitors from Human Trabecular Meshwork. Sci Rep. 2018; 8: 2814.

2. Du Y, Roh DS, Mann MM, Funderburgh ML, Funderburgh JL, Schuman JS. Multipotent stem cells from trabecular meshwork become phagocytic TM cells. Invest Ophthalmol Vis Sci. 2012; 53: 1566-75.

3. Stamer WD, Snyder RW, Smith BL, Agre P, Regan JW. Localization of aquaporin CHIP in the human eye: implications in the pathogenesis of glaucoma and other disorders of ocular fluid balance. Invest Ophthalmol Vis Sci. 1994; 35: 3867-72

4. Stamer WD, Seftor RE, Snyder RW, Regan JW. Cultured human trabecular meshwork cells express aquaporin-1 water channels. Curr Eye Res. 1995; 14: 1095-100.

5. Xue W, Comes N, Borras T. Presence of an established calcification marker in trabecular meshwork tissue of glaucoma donors. Invest Ophthalmol Vis Sci. 2007; 48: 3184-94.

6. Paez-Gonzalez P, Abdi K, Luciano D, Liu Y, Soriano-Navarro M, Rawlins E, et al. Ank3-dependent SVZ niche assembly is required for the continued production of new neurons. Neuron. 2011; 71: 61-75.

7. Gurdon JB. The transplantation of living cell nuclei. Adv Morphog. 1964; 4: 1-43.

8. Takahashi K, Yamanaka S. Induction of pluripotent stem cells from mouse embryonic and adult fibroblast cultures by defined factors. Cell. 2006; 126: 663-76. 
9. Yu J, Thomson JA. Pluripotent stem cell lines. Genes Dev. 2008; 22: 1987-97.

10. Mikkelsen TS, Hanna J, Zhang X, Ku M, Wernig M, Schorderet P, et al. Dissecting direct reprogramming through integrative genomic analysis. Nature. 2008; 454: 49-55.

11. Brambrink T, Foreman R, Welstead GG, Lengner CJ, Wernig M, Suh H, et al. Sequential expression of pluripotency markers during direct reprogramming of mouse somatic cells. Cell Stem Cell. 2008; 2: 151-9.

12. Maherali N, Sridharan R, Xie W, Utikal J, Eminli S, Arnold K, et al. Directly reprogrammed fibroblasts show global epigenetic remodeling and widespread tissue contribution. Cell Stem Cell. 2007; 1: 55-70.

13. Okita K, Ichisaka T, Yamanaka S. Generation of germline-competent induced pluripotent stem cells. Nature. 2007; 448: 313-7.

14. Wernig M, Meissner A, Foreman R, Brambrink T, Ku M, Hochedlinger K, et al. In vitro reprogramming of fibroblasts into a pluripotent ES-cell-like state. Nature. 2007; 448: 318-24.

15. Xie HT, Chen SY, Li GG, Tseng SC. Limbal epithelial stem/progenitor cells attract stromal niche cells by SDF-1/CXCR4 signaling to prevent differentiation. Stem Cells. 2011:29: 1874-85.

16. Chen SY, Han B, Zhu YT, Mahabole M, Huang J, Beebe DC, et al. HC-HA/PTX3 Purified from Amniotic Membrane Promotes BMP Signaling in Limbal Niche Cells to Maintain Quiescence of Limbal Epithelial Progenitor/Stem Cells. Stem Cells. 2015.

17. Guo P, Sun H, Zhang Y, Tighe S, Chen S, Su CW, et al. Limbal niche cells are a potent resource of adult mesenchymal progenitors. J Cell Mol Med. 2018; 22: 3315-22.

18. Han B, Chen SY, Zhu YT, Tseng SC. Integration of BMP/Wnt signaling to control clonal growth of limbal epithelial progenitor cells by niche cells. Stem Cell Res. 2014; 12 : 562-73.

19. Lin SL, Chang DC, Lin CH, Ying SY, Leu D, Wu DT. Regulation of somatic cell reprogramming through inducible mir-302 expression. Nucleic Acids Res. 2011; 39: 1054-65

20. Anokye-Danso F, Trivedi CM, Juhr D, Gupta M, Cui Z, Tian Y, et al. Highly efficient miRNA-mediated reprogramming of mouse and human somatic cells to pluripotency. Cell Stem Cell. 2011; 8: 376-88.

21. Miyoshi N, Ishii H, Nagano H, Haraguchi N, Dewi DL, Kano Y, et al. Reprogramming of mouse and human cells to pluripotency using mature microRNAs. Cell Stem Cell. 2011; 8: 633-8.

22. Du Y, Yun H, Yang E, Schuman JS. Stem cells from trabecular meshwork home to TM tissue in vivo. Invest Ophthalmol Vis Sci. 2013; 54: 1450-9.

23. Kelley MJ, Rose AY, Keller KE, Hessle H, Samples JR, Acott TS. Stem cells in the trabecular meshwork: present and future promises. Exp Eye Res. 2009; 88: $747-51$.

24. Li GG, Zhu YT, Xie HT, Chen SY, Tseng SC. Mesenchymal stem cells derived from human limbal niche cells. Invest Ophthalmol Vis Sci. 2012; 53: 5686-97.

25. Li GG, Chen SY, Xie HT, Zhu YT, Tseng SC. Angiogenesis potential of human limbal stromal niche cells. Invest Ophthalmol Vis Sci. 2012; 53: 3357-67.

26. Zhu YT, Chen HC, Chen SY, Tseng SC. Nuclear p120 catenin unlocks mitotic block of contact-inhibited human corneal endothelial monolayers without disrupting adherent junctions. JCell Sci. 2012; 125: 3636-48.

27. Zhu YT, Li F, Han B, Tighe S, Zhang S, Chen SY, et al. Activation of RhoA-ROCK-BMP signaling reprograms adult human corneal endothelial cells. JCell Biol. 2014

28. Chen J, Li Z, Zhang L, Ou S, Wang Y, He X, et al. Descemet's Membrane Supports Corneal Endothelial Cell Regeneration in Rabbits. Sci Rep. 2017; 7: 6983.

29. Liu Y, Sun H, Guo P, Hu M, Zhang Y, Tighe S, et al. Characterization and Prospective of Human Corneal Endothelial Progenitors. Int J Med Sci. 2017; 14: 705-10.

30. Lu WJ, Tseng SC, Chen S, Tighe S, Zhang Y, Liu X, et al. Senescence Mediated by p16INK4a Impedes Reprogramming of Human Corneal Endothelial Cells into Neural Crest Progenitors. Sci Rep. 2016; 6: 35166.

31. Zhu YT, Tighe S., Chen S., et al. Engineering of Human Corneal Endothelial Grafts. Current Ophthalmology Reports. 2015; 3: 207-17.

32. Liu X, Tseng SC, Zhang MC, Chen SY, Tighe S, Lu WJ, et al. LIF-JAK1-STAT3 signaling delays contact inhibition of human corneal endothelial cells. Cell Cycle. 2015; 14: 1197-206.

33. Zhu YT, Han B, Li F, Chen SY, Tighe S, Zhang S, et al. Knockdown of both p120 catenin and Kaiso promotes expansion of human corneal endothelial monolayers via RhoA-ROCK-noncanonical BMP-NFkappaB pathway. Invest Ophthalmol Vis Sci. 2014; 55: 1509-18.

34. Zhu YT, Hayashida Y, Kheirkhah A, He H, Chen SY, Tseng SC. Characterization and comparison of intercellular adherent junctions expressed by human corneal endothelial cells in vivo and in vitro. Invest OphthalmolVisSci. 2008; 49: 3879-86

35. Sun $\mathrm{H}$, Zhu Q, Guo P, Zhang Y, Tighe S, Zhu Y. Trabecular meshwork cells are a valuable resource for cellular therapy of glaucoma. J Cell Mol Med. 2019; 23: 1678-86

36. Pascolini D, Mariotti SP. Global estimates of visual impairment: 2010. Br J Ophthalmol. 2012; 96: 614-8.

37. Quigley HA, Broman AT. The number of people with glaucoma worldwide in 2010 and 2020. BrJOphthalmol. 2006; 90: 262-7.

38. Greco A, Rizzo MI, De Virgilio A, Gallo A, Fusconi M, de Vincentiis M. Emerging Concepts in Glaucoma and Review of the Literature. Am J Med. 2016; 129: 1000 e7- e13.
39. Friedman DS, Wilson MR, Liebmann JM, Fechtner RD, Weinreb RN An evidence-based assessment of risk factors for the progression of ocular hypertension and glaucoma. Am J Ophthalmol. 2004; 138: S19-31.

40. Le A, Mukesh BN, McCarty CA, Taylor HR. Risk factors associated with the incidence of open-angle glaucoma: the visual impairment project. Invest Ophthalmol Vis Sci. 2003; 44: 3783-9.

41. Levkovitch-Verbin H. Animal models of optic nerve diseases. Eye (Lond). 2004; 18: 1066-74.

42. Tamm ER, Russell P, Johnson DH, Piatigorsky J. Human and monkey trabecular meshwork accumulate alpha B-crystallin in response to heat shock and oxidative stress. Invest Ophthalmol Vis Sci. 1996; 37: 2402-13.

43. Acott TS, Kelley MJ. Extracellular matrix in the trabecular meshwork. Exp Eye Res. 2008; 86: 543-61.

44. Wordinger RJ, Clark AF. Bone morphogenetic proteins and their receptors in the eye. Exp Biol Med (Maywood). 2007; 232: 979-92.

45. Faralli JA, Schwinn MK, Gonzalez JM, Jr., Filla MS, Peters DM. Functional properties of fibronectin in the trabecular meshwork. Exp Eye Res. 2009; 88: 689-93.

46. Fleenor DL, Shepard AR, Hellberg PE, Jacobson N, Pang IH, Clark AF. TGFbeta2-induced changes in human trabecular meshwork: implications for intraocular pressure. Invest Ophthalmol Vis Sci. 2006; 47: 226-34.

47. Granstein RD, Staszewski R, Knisely TL, Zeira E, Nazareno R, Latina M, et al. Aqueous humor contains transforming growth factor-beta and a small (less than 3500 daltons) inhibitor of thymocyte proliferation. J Immunol. 1990; 144: $3021-7$.

48. Jampel HD, Roche N, Stark WJ, Roberts AB. Transforming growth factor-b in human aqueous humor. CurrEye Res. 1990; 9: 963-9.

49. Cousins SW, McCabe MM, Danielpour D, Streilein JW. Identification of transforming growth factor-beta as an immunosuppressive factor in aqueous humor. InvestOphthalmolVisSci. 1991; 32: 2201-11.

50. Pfeffer BA, Flanders KC, Guerin CJ, Danielpour D, Anderson DH. Transforming growth factor beta 2 is the predominant isoform in the neural retina, retinal pigment epithelium-choroid and vitreous of the monkey eye. Exp Eye Res. 1994; 59: 323-33.

51. Pena JD, Taylor AW, Ricard CS, Vidal I, Hernandez MR. Transforming growth factor beta isoforms in human optic nerve heads. Br J Ophthalmol. 1999; 83: 209-18.

52. Pasquale LR, Dorman-Pease ME, Lutty GA, Quigley HA, Jampel HD. Immunolocalization of TGF-b1, TGF-b2, and TGF-b3 in the anterior segment of the human eye. InvestOphthalmolVisSci. 1993; 34: 23-30.

53. Tripathi RC, Chan WF, Li J, Tripathi BJ. Trabecular cells express the TGF-beta 2 gene and secrete the cytokine. Exp Eye Res. 1994; 58: 523-8.

54. Inatani M, Tanihara H, Katsuta H, Honjo M, Kido N, Honda Y. Transforming growth factor-beta 2 levels in aqueous humor of glaucomatous eyes. Graefes Arch Clin Exp Ophthalmol. 2001; 239: 109-13.

55. Schlotzer-Schrehardt U, Zenkel M, Kuchle M, Sakai LY, Naumann GO. Role of transforming growth factor-beta1 and its latent form binding protein in pseudoexfoliation syndrome. Exp Eye Res. 2001; 73: 765-80.

56. Yoneda K, Nakano M, Mori K, Kinoshita S, Tashiro K. Disease-related quantitation of TGF-beta3 in human aqueous humor. Growth Factors. 2007; 25: 160-7.

57. Horiguchi K, Sakamoto K, Koinuma D, Semba K, Inoue A, Inoue S, et al. TGF-beta drives epithelial-mesenchymal transition through deltaEF1-mediated downregulation of ESRP. Oncogene. 2012; 31: 3190-201.

58. Taylor SE, Vaughan-Thomas A, Clements DN, Pinchbeck G, Macrory LC, Smith RK, et al. Gene expression markers of tendon fibroblasts in normal and diseased tissue compared to monolayer and three dimensional culture systems. BMCMusculoskeletDisord. 2009; 10: 27.

59. De Groef L, Van Hove I, Dekeyster E, Stalmans I, Moons L. MMPs in the trabecular meshwork: promising targets for future glaucoma therapies? Invest Ophthalmol Vis Sci. 2013; 54: 7756-63.

60. Inoue $\mathrm{T}$, Ohbayashi $\mathrm{T}$, Fujikawa $\mathrm{Y}$, Yoshida $\mathrm{H}$, Akama TO, Noda $\mathrm{K}$, et al. Latent TGF-beta binding protein-2 is essential for the development of ciliary zonule microfibrils. Hum Mol Genet. 2014; 23: 5672-82.

61. Kuehn MH, Lipsett KA, Menotti-Raymond M, Whitmore SS, Scheetz TE, David VA, et al. Correction: A Mutation in LTBP2 Causes Congenital Glaucoma in Domestic Cats (Felis catus). PLoS One. 2016; 11: e0161517.

62. Fuchshofer R, Welge-Lussen U, Lutjen-Drecoll E. The effect of TGF-beta2 on human trabecular meshwork extracellular proteolytic system. Exp Eye Res. 2003; 77: 757-65.

63. Zhao X, Ramsey KE, Stephan DA, Russell P. Gene and protein expression changes in human trabecular meshwork cells treated with transforming growth factor-beta. Invest Ophthalmol Vis Sci. 2004; 45: 4023-34.

64. Welge-Lussen U, May CA, Lutjen-Drecoll E. Induction of tissue transglutaminase in the trabecular meshwork by TGF-beta1 and TGF-beta2. Invest Ophthalmol Vis Sci. 2000; 41: 2229-38.

65. Tovar-Vidales $\mathrm{T}$, Clark AF, Wordinger RJ. Focus on molecules: transglutaminase 2. Exp Eye Res. 2011; 93: 2-3.

66. Tovar-Vidales $\mathrm{T}$, Roque $\mathrm{R}$, Clark AF, Wordinger RJ. Tissue transglutaminase expression and activity in normal and glaucomatous human trabecular meshwork cells and tissues. Invest Ophthalmol Vis Sci. 2008; 49: 622-8.

67. Last JA, Pan T, Ding Y, Reilly CM, Keller K, Acott TS, et al. Elastic modulus determination of normal and glaucomatous human trabecular meshwork. Invest Ophthalmol Vis Sci. 2011; 52: 2147-52. 
68. Dan J, Belyea D, Gertner G, Leshem I, Lusky M, Miskin R. Plasminogen activator inhibitor-1 in the aqueous humor of patients with and without glaucoma. Arch Ophthalmol. 2005; 123: 220-4.

69. Clark AF, Wilson K, McCartney MD, Miggans ST, Kunkle M, Howe W. Glucocorticoid-induced formation of cross-linked actin networks in cultured human trabecular meshwork cells. Invest Ophthalmol Vis Sci. 1994; 35: 281-94.

70. O'Reilly S, Pollock N, Currie L, Paraoan L, Clark AF, Grierson I. Inducers of cross-linked actin networks in trabecular meshwork cells. Invest Ophthalmol Vis Sci. 2011; 52: 7316-24

71. Bouchemi M, Roubeix C, Kessal K, Riancho L, Raveu AL, Soualmia H, et al. Effect of benzalkonium chloride on trabecular meshwork cells in a new in vitro 3D trabecular meshwork model for glaucoma. Toxicol In Vitro. 2017; 41: 21-9.

72. Filla MS, Schwinn MK, Nosie AK Clark RW, Peters DM. Dexamethasone-associated cross-linked actin network formation in human trabecular meshwork cells involves beta3 integrin signaling. Invest Ophthalmol Vis Sci. 2011; 52: 2952-9. 